The BMJ

Cite this as: BMJ 2021;374:n2215 http://dx.doi.org/10.1136/bmi.n2215 Published: 13 September 2021

\section{How can I manage conflict in my team?}

\section{Disagreements within teams can be difficult but there are ways to manage conflict and nurture positive working relationships, Abi Rimmer hears}

\section{Abi Rimmer}

\section{What isn't being said?}

Rachel Morris, GP, speaker, coach, and host of the You Are Not A Frog podcast, says: “No one enjoys conflict, and in healthcare, where we pride ourselves on being kind and compassionate, we'll do anything to avoid it. However, avoiding conflict seldom makes the underlying problems go away and conflict left to fester creates bigger problems.

"With conflict there are always two things going on-what is said and what is unsaid. Inevitably, it's what is unsaid which is running the show. A colleague may be openly critical of another person in the team, but behind this may be a feeling of not being valued or worry that they themselves aren't coping.

“Asking someone, 'What's the story in your head?' about a situation can help reveal their underlying assumptions (often wrong), their beliefs (often unduly negative), and concerns (often exaggerated). Once you understand these, you can explore what is true. The good news is that, as clinicians, we already know how to do this with patients: remember ICE-ideas, concerns, expectations?

"Creating a safe space for the team to speak up and explore their concerns will help facilitate constructive conflict, so that problems can be tackled before they turn toxic. You could actively mine for conflict-for example, in a meeting, go round asking everyone to give two reasons why a suggested change might not work, or get people to play different roles such as 'devil's advocate' and 'unconditional supporter.'

"To get people to speak up honestly, it's vital to build trust, so that people know that their relationships won't be harmed if they express concern or disagree. Trust is built by getting to know each other better, by sharing when you've got things wrong, and by modelling vulnerability.

"Letting unexpressed conflict fester is profoundly destructive for teams. If you feel out of your depth, don't be afraid to ask for some professional help from a mediator or a coach."

\section{Encourage constructive conflict}

Meenal Galal, emergency medicine consultant and trustee of You okay doc? says: "Firstly, it’s important to remember that conflict in teams is both inevitable and necessary. It's poorly managed conflict that leads to negative patient outcomes and poor team performance.

"Constructive conflict, however, can improve clinical performance (and therefore patient care), improve clinical safety, and create a stimulating learning environment. It embraces different ideas and perspectives and seeks to discover solutions collaboratively.

"Try assessing the problem from a systems perspective, rather than an individual perspective, avoid 'buts,' and rely on objective data as far as is possible. Also try to avoid generalisations and promote shared solution finding.

"At a departmental and trust level, constructive conflict can only happen within a culture that promotes inclusivity, psychological safety, and trust.

"There are several factors that could undermine a culture of constructive conflict and that need to be avoided. The first is a fear of failure within a team, or an unhealthy competitive atmosphere. It's important that your team have a sense of job security and are not under an unusual level of pressure to perform.

"The second is a lack of psychological safety, where teams have their confidence hit by management or there are no rules in place around how to have a respectful conversation.

"The third is a 'groupthink' where leaders discourage differing opinions or feedback and they avoid conflict.

"And, finally, a lack of trust within a team-for example where people feel unable to speak up during meetings but share their negative views offline-can prevent team conflicting in a constructive way.

"If you notice or experience any of these behaviours in your team, speak to your clinical lead or educational supervisor and document events as well as you can remember them, at the time.

"Remember that we're all aspiring towards a shared vision of exemplary clinical performance, good clinical outcomes, positive patient experience, and adherence to gold standards and clinical governance."

\section{Make everyone feel heard}

Trevor Bibic, learning and development consultant for Brightbloom Training, says, "These are my hard earnt lessons from years of trial and error. Conflicts don't exist in a vacuum and affect everyone around them. It's best to deal with the conflict as early as possible before it gets bigger or starts to affect others.

"It's tempting to do nothing and hope it goes away. After all, you've probably got something even more pressing to do. However, no matter how difficult or awkward it is now, it rarely gets easier and often escalates. 
"I'm also a firm believer that no one gets up in the morning wanting to get into or cause conflict-it's exhausting. Avoid the 'problem person' mentality and don't get drawn into it by others.

"Take the time to really listen to those involved and make sure you confirm that you've understood their perspective correctly. Until they feel heard, then they're not likely to collaborate towards a resolution. This is important even when you have intuitively figured things out and genuinely know the way forward.

"Once looking to move towards resolution, try to create as much value for all parties as possible. I like the 'Getting to Yes' negotiation principles ${ }^{1}$ as a practical guide to help with this.

"And, finally, be pre-emptive-agree with your team how you will all handle resolving conflicts before they happen."

Trevor Bibic and Rachel Morris will be delivering seminar sessions at the BMJ Live online conference, taking place on 7-9 October 2021. Register FREE at live.bmj.com

You can listen to the You Are Not A Frog podcast at www.youarenotafrog.com.

1 Shonk K. Six guidelines for "getting to yes." 15 October 2020. www.pon.harvard.edu/daily/negotiation-skills-daily/six-guidelines-for-getting-to-yes. 